\title{
A Robust Calcium-Organic Framework for Effective Separation of Xenon and Krypton
}

Li Wang, Wenping Liu, Jie Ding, Hualian Zhang, Yudie Zhu, Feng Luo*

State Key Laboratory of Nuclear Resources and Environment, School of Chemistry,

Biology and Materials Science, East China University of Technology, Nanchang

330013, P. R. China.

Email: ecitluofeng@163.com 


\section{Experimental}

\section{Materials and reagents}

The ligand of $\mathrm{H}_{4}$ TBAPy was purchased from Jilin Chinese Academy of Sciences-Yanshen Technology Co.,Ltd. All other reagents and solvents including $\mathrm{Ca}\left(\mathrm{NO}_{3}\right)_{2} \cdot 4 \mathrm{H}_{2} \mathrm{O}$, hydrochloric (HCl), N, N-Dimethylformamide (DMF), and methanol were purchased from commercial sources without further purification.

\section{Synthesis of ECUT-50a}

The bulk ECUT-50 were immersed into methanol for three days. The methanol was changed three times every day. After that, the products were evacuated at $180{ }^{\circ} \mathrm{C}$ under vacuum condition (ECUT-50a).

\section{Single Crystal X-ray diffraction}

After synthesis, one yellow crystal with suitable size was selected from the mother liquor and mounted on the tip of glass fibre. The data collection of the single crystal was performed on a Bruker-AXS SMART Breeze CCD diffractometer using graphite monochromated Mo Ka radiation $(\lambda=0.71073 \AA)$. The structure was solved by direct method and refined by full-matrix least-squares using SHELXTL program package.2.7. The selected crystallographic data and refinement parameters for the single crystal are summarized in Table S1. Selected bond lengths and angles for ECUT-50 are listed in Table S2. Crystallographic data for the structure of ECUT50 have been deposited in CIF format in Cambridge Crystallographic Data Center with CCDC 1974915.

\section{Physical Measurements}


The powder X-ray diffraction (PXRD) patterns were recorded using $\mathrm{Cu} \mathrm{K} \alpha$ radiation $(\lambda=1.5406$ $\AA$ ) on AXSD8 Discover powder diffractometer at $40 \mathrm{kV}, 40 \mathrm{~mA}$ at room temperature in the range of 5-50 degree (2 theta). Thermal gravimetric analysis (TGA) was carried out using a TGA Q500 thermal analysis system and the sample was heated from 30 to $800{ }^{\circ} \mathrm{C}$ under $\mathrm{N}_{2}$ atmosphere with a heating rate of $10{ }^{\circ} \mathrm{C} / \mathrm{min}$. The data analysis was carried out using the TA Universal Analysis software package.

\section{Gas adsorption experiments and calculations}

The gas sorption isotherms were collected on a Belsorp-max. Ultrahigh purity grade Xe (99.99\%) and $\operatorname{Kr}(99.99 \%)$ were used for the measurements. To maintain the experimental temperatures, liquid nitrogen $(77 \mathrm{~K})$ and temperature-programmed water bath (273 and $298 \mathrm{~K})$ were used, respectively. A roughly $100 \mathrm{mg}$ of ECUT-50a were taken for the nitrogen adsorption experiments at $77 \mathrm{~K}$. The adsorption isotherms for $\mathrm{Xe} / \mathrm{Kr}$ were obtained at temperature of $273 \mathrm{~K}$ and $298 \mathrm{~K}$, respectively. The isosteric heats of adsorption $\left(\mathrm{Q}_{\mathrm{st}}\right)$ were calculated based on Clausius-Clapeyron equation using dual-site Langmuir-Freundlich model with the following equation.

$Q_{s t}=R T^{2}\left(\frac{\partial \ln p}{\partial T}\right)_{q}$

The adsorption selectivity was established by the Ideal Adsorbed Solution Theory (IAST) for $\mathrm{Xe} / \mathrm{Kr}(20: 80)$ at $298 \mathrm{~K}$. The adsorption selectivity was calculated from

$$
S_{a d s}=\frac{q_{A} / q_{B}}{y_{A} / y_{B}}
$$

where the $\mathrm{q}_{\mathrm{A}}$, and $\mathrm{q}_{\mathrm{B}}$ represent the molar loadings in ECUT-50 that is in equilibrium with a bulk fluid mixture with mole fractions $\mathrm{y}_{\mathrm{A}}$, and $\mathrm{y}_{\mathrm{B}}=1-\mathrm{y}_{\mathrm{A}}$. The molar loadings, also called gravimetric uptake capacities, are expressed in mol $\mathrm{kg}^{-1}$. The IAST calculations for the mixtures were 
performed at $298 \mathrm{~K}$, taking the mole fractions $\mathrm{y}_{\mathrm{A}}=0.2$ and $\mathrm{y}_{\mathrm{B}}=1-\mathrm{y}_{\mathrm{A}}=0.8$.

\section{Breakthrough experiment}

The breakthrough experiments were carried out at $298 \mathrm{~K}$. The powder of ECUT-50a were packed into column. Firstly, the pure helium gas $(100 \mathrm{ml} / \mathrm{min})$ flow through the column for 30 min. Then the $\mathrm{Xe} / \mathrm{Kr}$ gas mixture (20/80) passed through the fixed bed column with a flow rate of $2 \mathrm{~mL} / \mathrm{min}$. The effluent gases from the column were monitored by a gas chromatography (TCDThermal Conductivity Detector, detection limit $0.1 \%$ ). 
Table S1. Crystal structure information for ECUT-50.

\begin{tabular}{ll}
\hline Compound & ECUT-50 \\
\hline Formula & $\mathrm{C}_{22} \mathrm{H}_{13} \mathrm{CaO}_{5}$ \\
Formula weight & 397.40 \\
Color & light yellow \\
Crystal system & orthorhombic \\
Space group & Pbam \\
$\mathrm{a}(\AA)$ & $20.371(6)$ \\
$\mathrm{b}(\AA)$ & $6.895(2)$ \\
C $(\AA)$ & $16.506(5)$ \\
$\alpha$ & 90.00 \\
$\beta$ & 90.00 \\
$\gamma$ & 90.00 \\
Volume $\left(\AA^{3}\right)$ & 2318.4 \\
$Z$ & 4 \\
Temperature for data collection & 296 \\
Final & \\
Range for data collection $\theta\left(^{\circ}\right)$ & 1.234 to 25 \\
No. of measured reflections & 11208 \\
No. of unique reflections & 2124 \\
No. of parameters & 138 \\
No. of restraints & $\mathrm{R}_{1}=0.1440$, \\
Goodness-of-fit on $\mathrm{F}^{2}$ & 1.173 \\
\hline & \\
\hline &
\end{tabular}




$$
{ }^{\mathrm{a}} R_{1}=\Sigma|| F_{\mathrm{o}}|-| F_{\mathrm{c}}|/ \Sigma| \overline{F_{\mathrm{o}} \mid \cdot{ }^{\mathrm{b}} w R_{2}=\left[\Sigma w\left(F_{\mathrm{o}}{ }^{2}-F_{\mathrm{c}}{ }^{2}\right)^{2} / \Sigma w\left(F_{\mathrm{o}}\right)^{2}\right]^{1 / 2}}
$$

\begin{tabular}{|c|c|c|c|}
\hline Bond length & & & \\
\hline $\mathrm{Ca}(1)-\mathrm{O}(2) \# 1$ & $2.312(4)$ & $\mathrm{Ca}(1)-\mathrm{O}(1)$ & $2.506(6)$ \\
\hline $\mathrm{Ca}(1)-\mathrm{O}(2) \# 2$ & $2.312(4)$ & $\mathrm{Ca}(1)-\mathrm{O}(2)$ & $11(4)$ \\
\hline $\mathrm{Ca}(1)-\mathrm{O}(3) \# 3$ & $2.423(4)$ & $\mathrm{Ca}(1)-\mathrm{O}(2) \# 3$ & $511(4)$ \\
\hline $\mathrm{Ca}(1)-\mathrm{O}(3)$ & $2.423(4)$ & $\mathrm{Ca}(1)-\mathrm{O}(1) \# 4$ & $37(6)$ \\
\hline Symmetrical code: \#1 & $1-\mathrm{X}, 3-\mathrm{Y},+\mathrm{Z}$ & $\# 2$ 1/2-X,-1/2+Y,-Z; \#3 1/ & $/ 2-\mathrm{X},-1 / 2+\mathrm{Y},+\mathrm{Z}$ \\
\hline Bond angles & & & \\
\hline $\mathrm{O}(2) \# 1-\mathrm{Ca}(1)-\mathrm{O}(2) \# 2$ & $279.2(2)$ & $\mathrm{O}(1)-\mathrm{Ca}(1)-\mathrm{O}(2)$ & $132.94(12)$ \\
\hline $\mathrm{O}(2) \# 1-\mathrm{Ca}(1)-\mathrm{O}(3) \# 3$ & 3 86.68(19) & $\mathrm{O}(2) \# 1-\mathrm{Ca}(1)-\mathrm{O}(2)$ & \#3 98.18(15) \\
\hline $\mathrm{O}(2) \# 2-\mathrm{Ca}(1)-\mathrm{O}(3) \# 3$ & $3153.00(17)$ & $\mathrm{O}(2) \# 2-\mathrm{Ca}(1)-\mathrm{O}(2) \#$ & $\neq 3 \quad 153.02(11)$ \\
\hline $\mathrm{O}(2) \# 1-\mathrm{Ca}(1)-\mathrm{O}(3)$ & $153.00(17)$ & $\mathrm{O}(3) \# 3-\mathrm{Ca}(1)-\mathrm{O}(2) \# 3$ & $3 \quad 51.54(14)$ \\
\hline $\mathrm{O}(2) \# 2-\mathrm{Ca}(1)-\mathrm{O}(3)$ & $86.68(19)$ & $\mathrm{O}(3)-\mathrm{Ca}(1)-\mathrm{O}(2) \# 3$ & $104.60(18)$ \\
\hline $\mathrm{O}(3) \# 3-\mathrm{Ca}(1)-\mathrm{O}(3)$ & $96.2(3)$ & $\mathrm{O}(1)-\mathrm{Ca}(1)-\mathrm{O}(2) \# 3$ & $132.94(12)$ \\
\hline $\mathrm{O}(2) \# 1-\mathrm{Ca}(1)-\mathrm{O}(1)$ & $72.27(14)$ & $\mathrm{O}(2)-\mathrm{Ca}(1)-\mathrm{O}(2) \# 3$ & 71.93(18) \\
\hline $\mathrm{O}(2) \# 2-\mathrm{Ca}(1)-\mathrm{O}(1)$ & $72.27(14)$ & $\mathrm{O}(2) \# 1-\mathrm{Ca}(1)-\mathrm{O}(1) \# 4$ & $84.40(15)$ \\
\hline $\mathrm{O}(3) \# 3-\mathrm{Ca}(1)-\mathrm{O}(1)$ & $81.57(15)$ & $\mathrm{O}(2) \# 2-\mathrm{Ca}(1)-\mathrm{O}(1) \# 4$ & $4.40(15)$ \\
\hline $\mathrm{O}(3)-\mathrm{Ca}(1)-\mathrm{O}(1)$ & $81.57(15)$ & $\mathrm{O}(3) \# 3-\mathrm{Ca}(1)-\mathrm{O}(1) \# 4$ & $117.23(14)$ \\
\hline $\mathrm{O}(2) \# 1-\mathrm{Ca}(1)-\mathrm{O}(2)$ & $153.02(11)$ & $\mathrm{O}(3)-\mathrm{Ca}(1)-\mathrm{O}(1) \# 4$ & $117.23(14)$ \\
\hline $\mathrm{O}(2) \# 2-\mathrm{Ca}(1)-\mathrm{O}(2)$ & $98.18(15)$ & $\mathrm{O}(1)-\mathrm{Ca}(1)-\mathrm{O}(7)$ & $149.4(2)$ \\
\hline $\mathrm{O}(3) \# 3-\mathrm{Ca}(1)-\mathrm{O}(2)$ & $104.60(18)$ & $\mathrm{O}(2)-\mathrm{Ca}(1)-\mathrm{O}(1) \# 4$ & $68.63(14)$ \\
\hline $\mathrm{O}(3)-\mathrm{Ca}(1)-\mathrm{O}(2)$ & $51.54(14)$ & $\mathrm{O}(2)-\mathrm{Ca}(1)-\mathrm{O}(1) \# 4$ & $68.63(14)$ \\
\hline
\end{tabular}

Table S2 Selected bond length $(\AA)$ and angles $\left({ }^{\circ}\right)$ for ECUT-50 


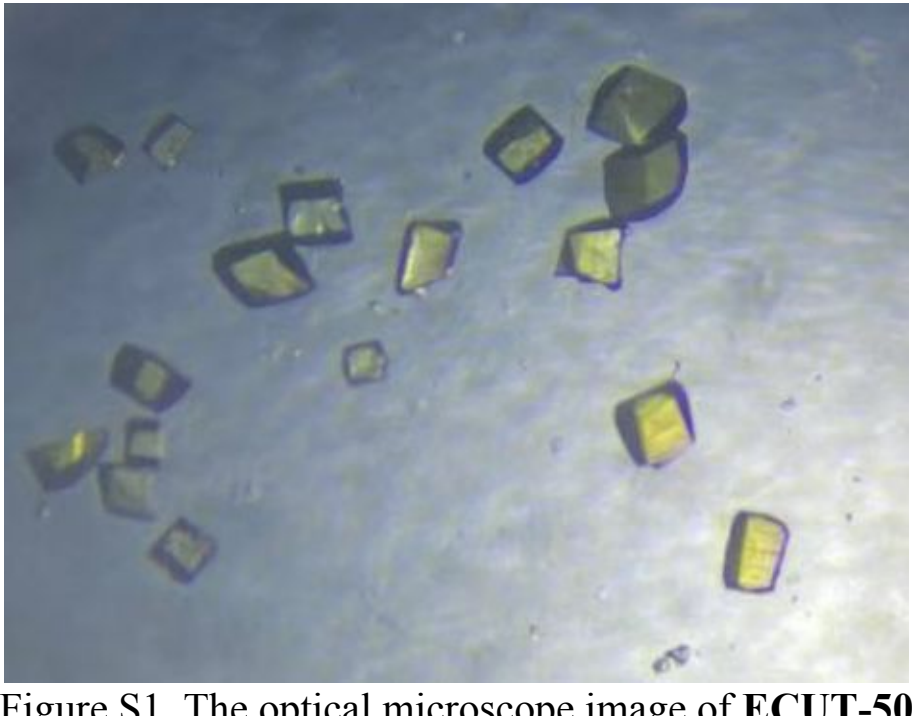

Figure S1. The optical microscope image of ECUT-50 


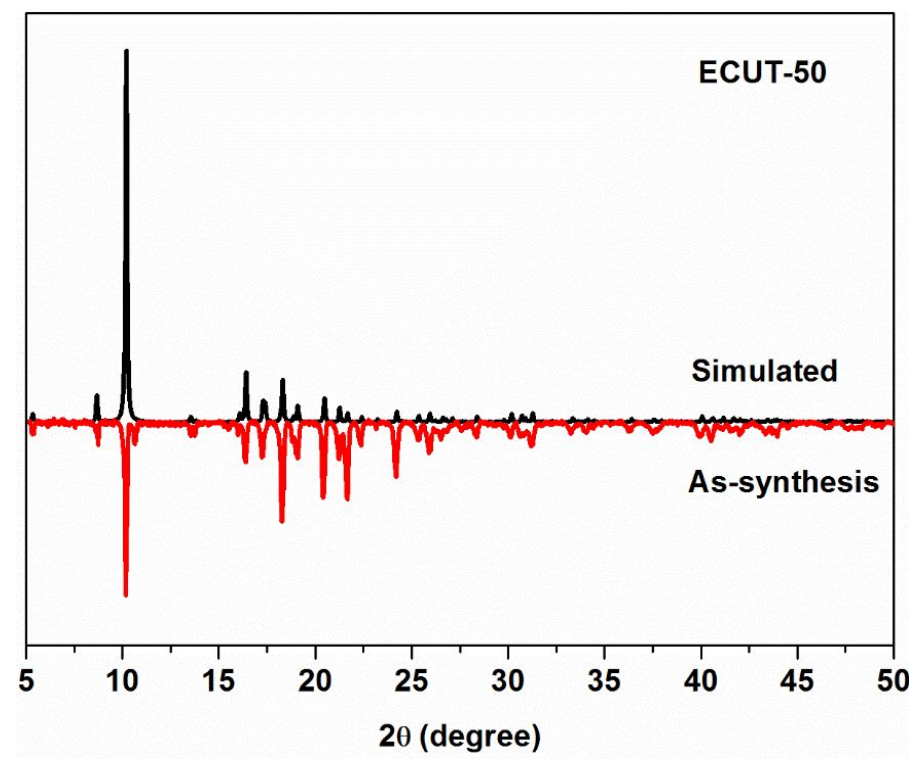

Figure S2. The PXRD patterns of ECUT-50 with as-synthesized samples and the PXRD patterns simulated from single crystal data. 


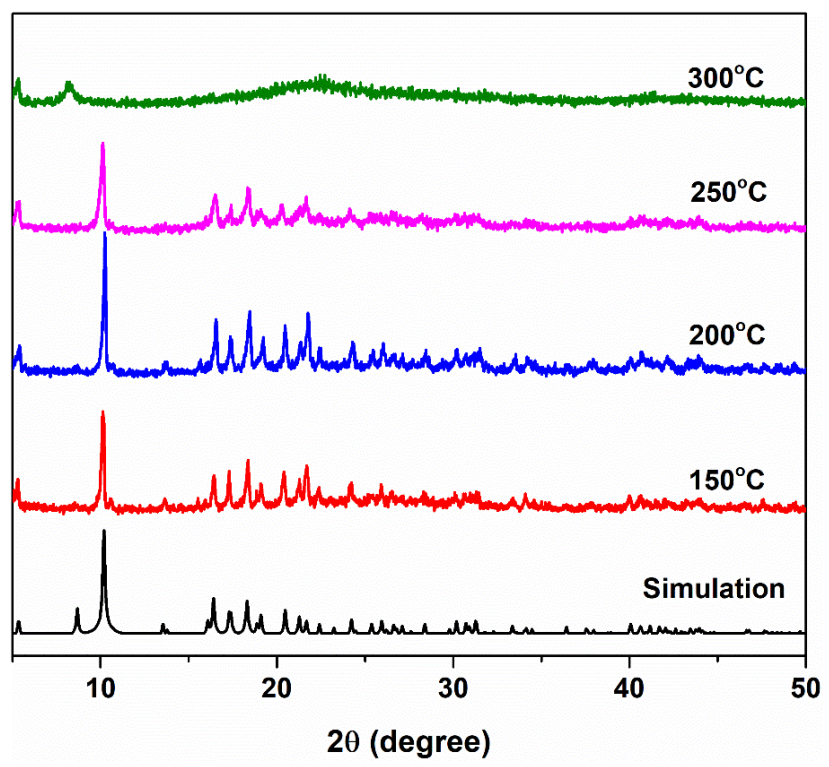

Figure S3. Thermal stability from $150^{\circ} \mathrm{C}$ to $300^{\circ} \mathrm{C}$ of ECUT-50 including the simulated result. 


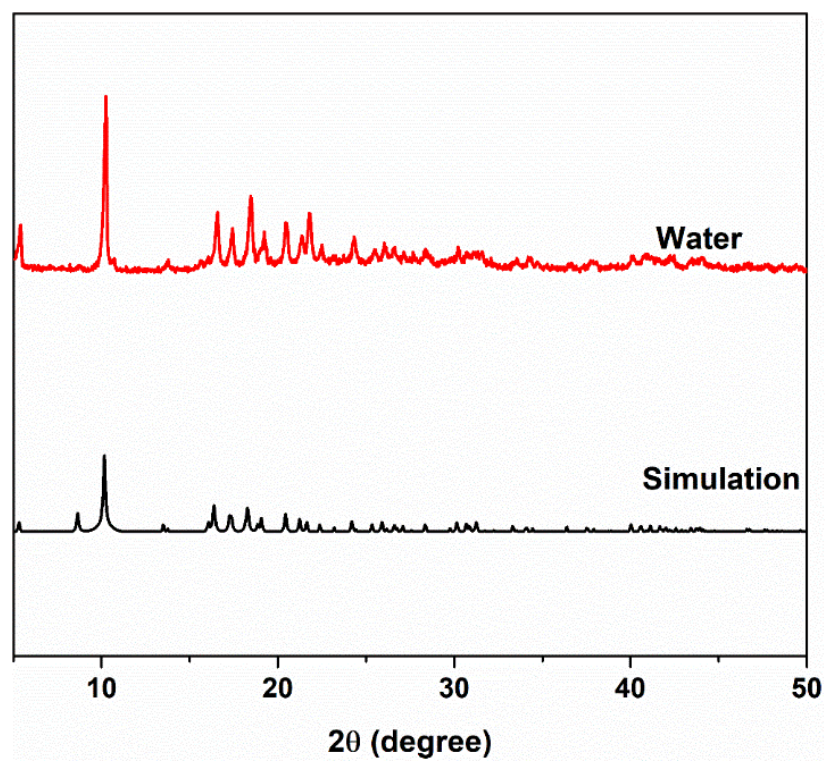

Figure S4. PXRD patterns of ECUT-50 after immersed into water including the simulated result. 


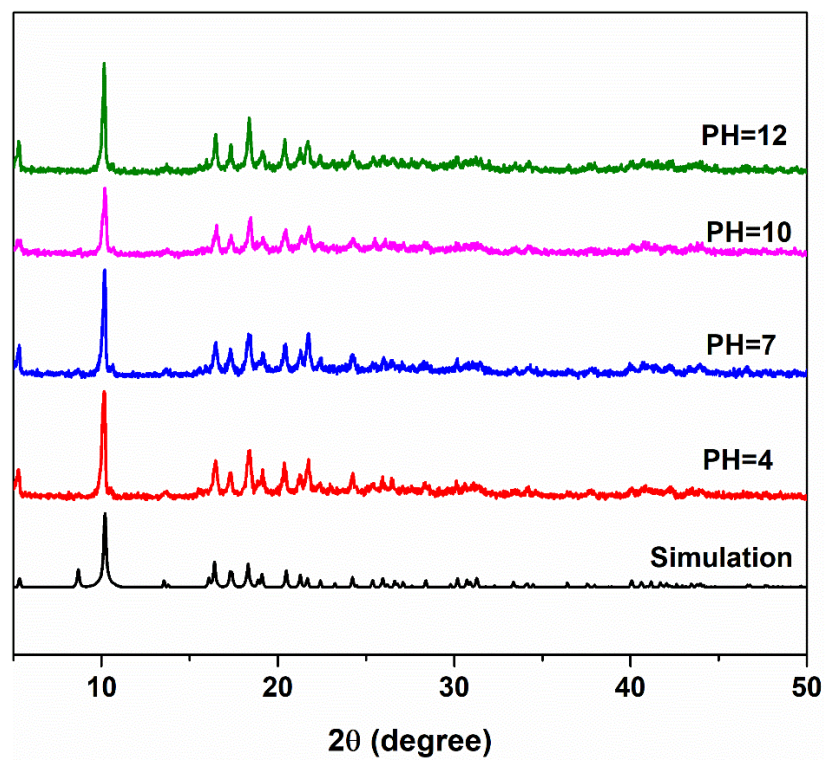

Figure S5. PXRD patterns of ECUT-50 after soaking in different $\mathrm{pH}$ values including the simulated result. 


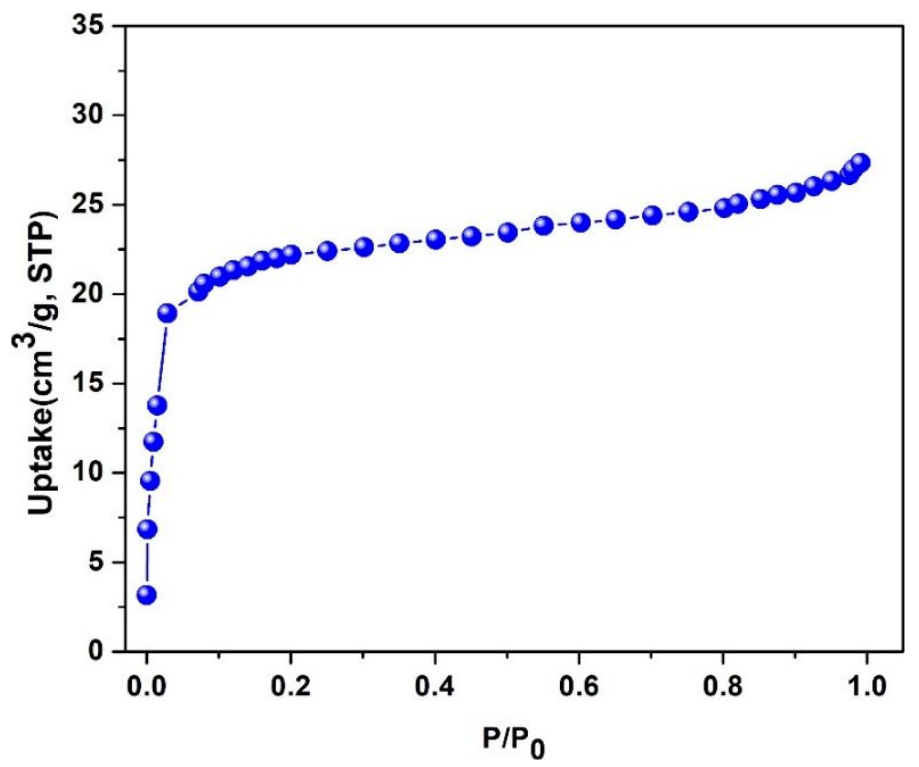

Figure S6. N2 adsorption isotherms of ECUT-50a at $77 \mathrm{~K}$. 


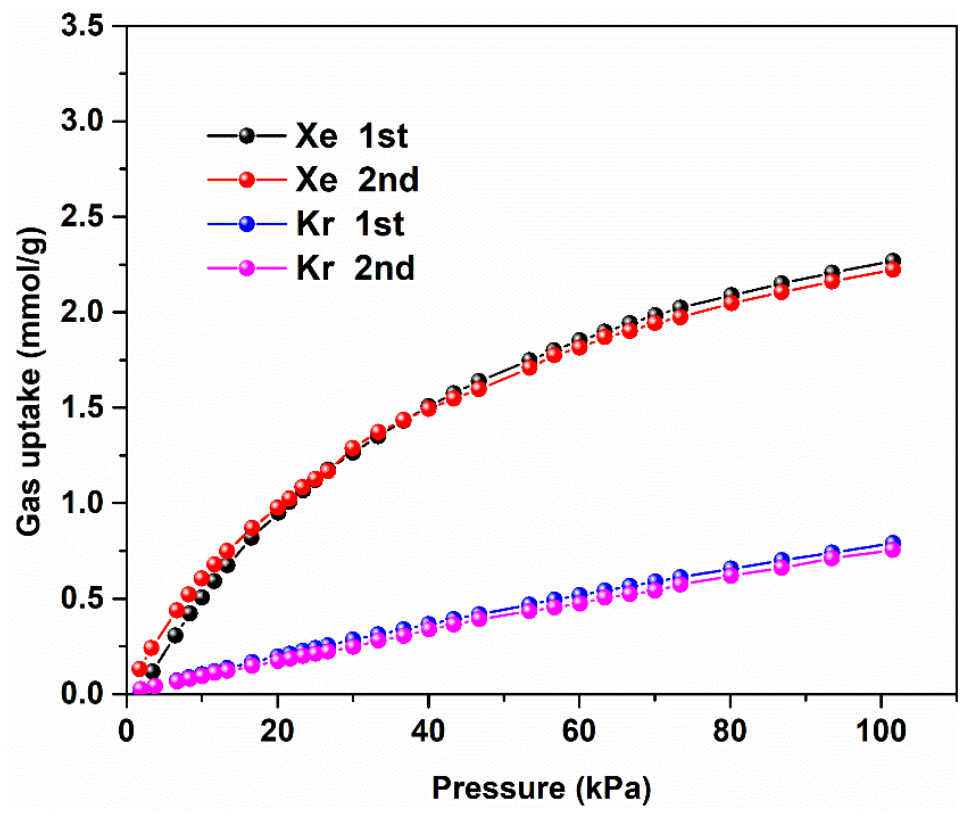

Figure S7. Two cycles adsorption isotherms for $\mathrm{Xe}$ and $\mathrm{Kr}$. 


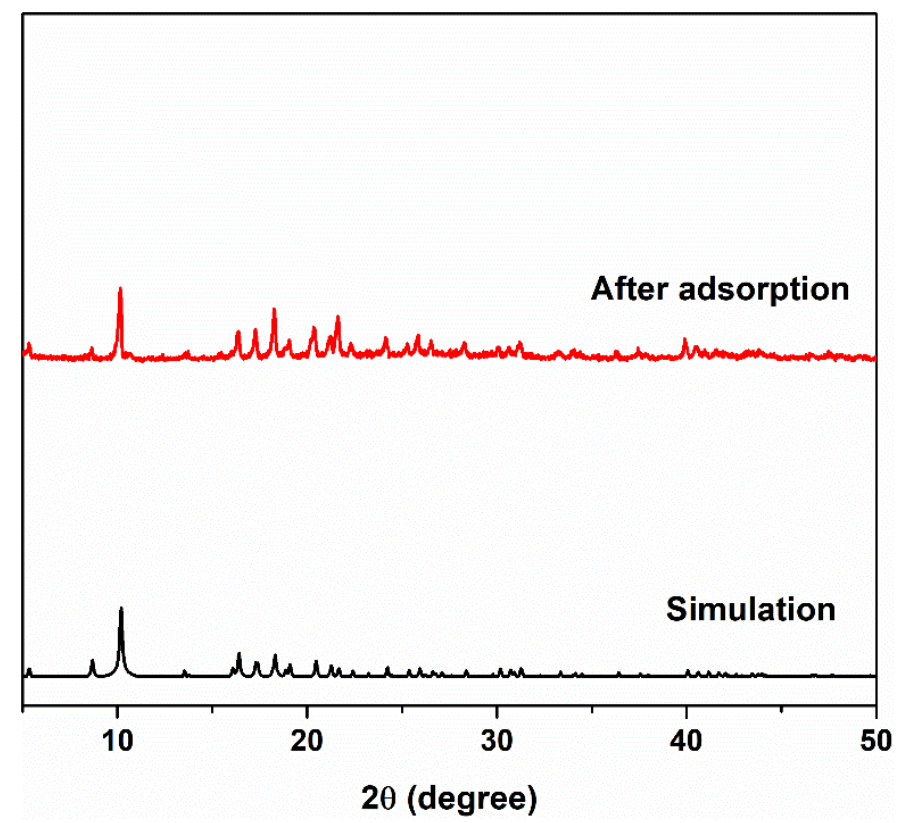

Figure S8. PXRD patterns of ECUT-50 after two cycles adsorption including simulated result. 

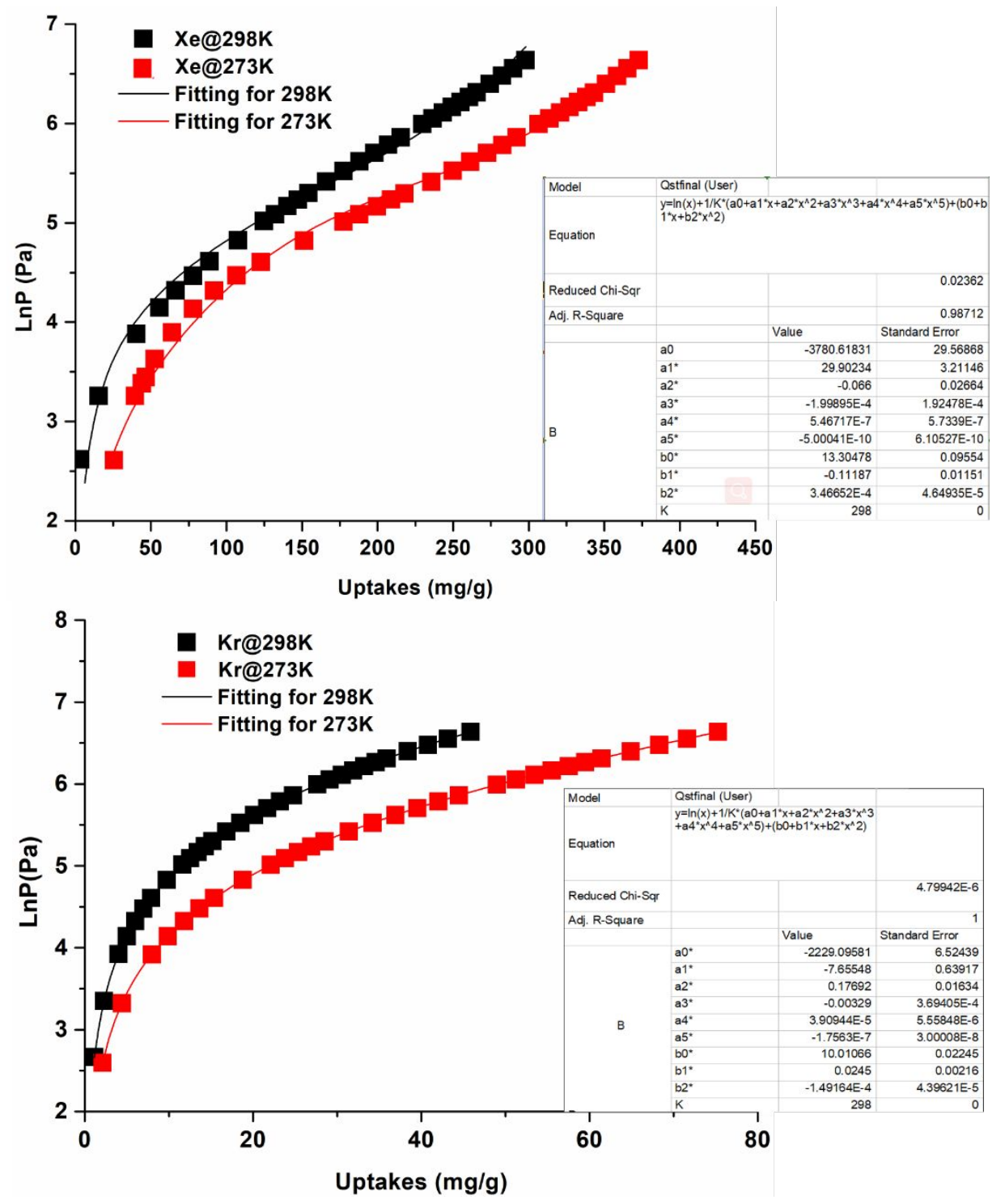

Figure S9. The fitting curves for adsorption isotherms of ECUT-50 for Xe and $\mathrm{Kr}$ 


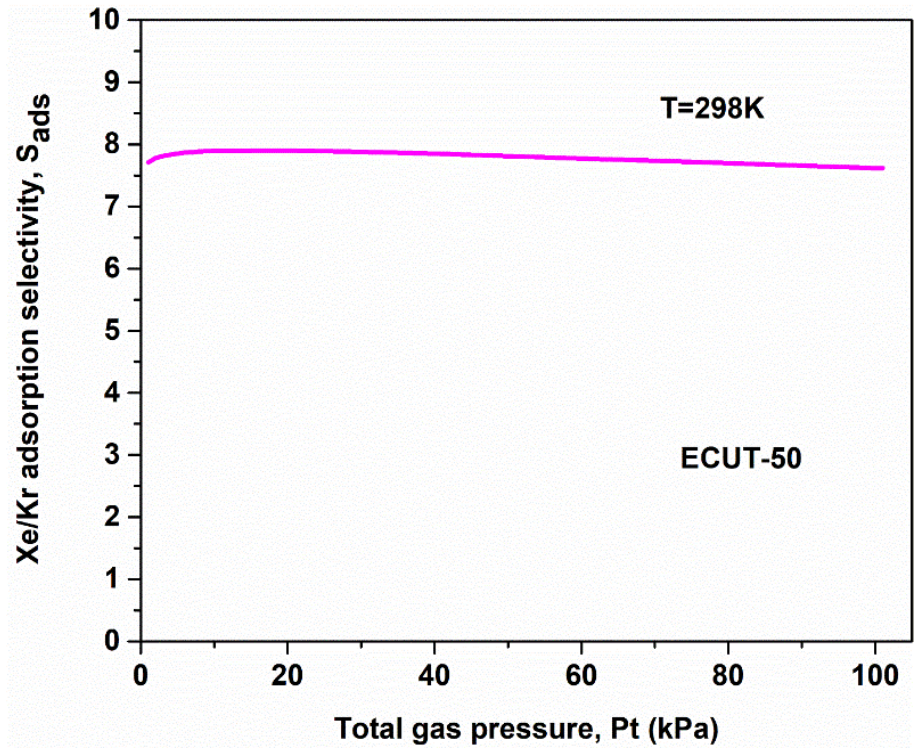

Figure S10. The calculated IAST selectivity for Xe/Kr (20/80) of ECUT-50 at $298 \mathrm{~K}$ 


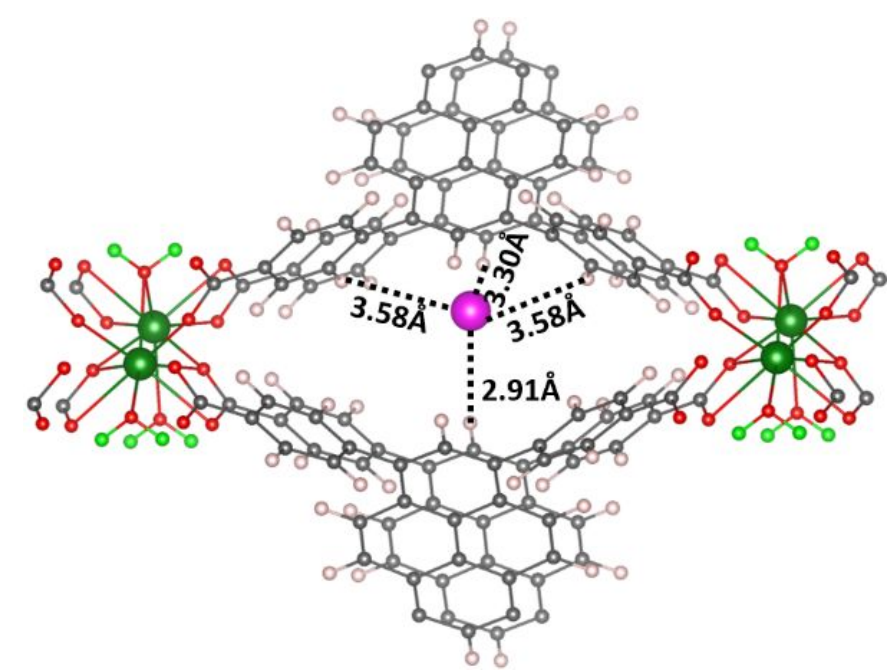

Figure S11. The binding sites of Xe in ECUT-50 